\section{AB0733 PSORIATIC ARTHRITIS IN NIGERIAN PSORIASIS PATIENTS - MYTH OR A MISSING LINK?}

A. I. M. Ajibade ${ }^{1}$, O. O. Ayanlowo ${ }^{2}$, U. Ima-Edomwonyi ${ }^{3}$, A. J. Egwuenu', O. Adelowo ${ }^{5} .{ }^{1}$ Obafemi Awolowo University Teaching Hospitals Complex, Rheumatology Unit, Internal Medicine, Ile-Ife, Nigeria; ${ }^{2}$ Faculty of Clinical Sciences, College of Medicine, University of Lagos, Internal Medicine, Lagos, Nigeria; ${ }^{3}$ Lagos University Teaching Hospital, Rheumatology Unit, Internal Medicine, Lagos, Nigeria; ${ }^{4}$ Nigeria Centre for Disease Control, Jabi, Abuja, Nigeria; ${ }^{5}$ Lagos State University Teaching Hospital, Rheumatology Unit, Internal Medicine, Lagos, Nigeria

Background: Beyond true arthritis, Psoriatic arthritis (PsA) is known with dactylitis and enthesitis. Enthesitis is postulated as the central pathogenic process in seronegative spondyloarthritis ${ }^{1}$, and the primary finding in psoriatic arthritis ${ }^{2}$. Psoriasis (and more so PsA) were initially thought to be rare in West Africa. Psoriasis $(P s)$ is now reported increasingly in Nigeria. But the notion of the rarity of PsA still remains in the absence of systematic documentation of PsA among psoriasis patients, with few cases reported from Rheumatology clinics ${ }^{3}$.

Objectives: This study set out to determine the prevalence of PsA among Nigerian Ps patients using the Classification for Psoriatic Arthritis (CASPAR) criteria, and to evaluate enthesitis amongst them.

Methods: This hospital-based, cross-sectional study was carried out at the dermatology clinic over an 18-month period. All patients seen within the study period with biopsy-established Ps were recruited. Fifty-three (53) Ps patients, 16 years or older, were enrolled. The CASPAR criteria was used to diagnose PsA. A modified Spondyloarthritis Research Consortium of Canada (SPARCC) enthesitis chart was used to document entheseal inflammation sites. Diagnosis of enthesitis was made by clinical examination.

Results: Fourteen participants fulfilled the CASPAR criteria (8 females, 6 males, $\mathrm{F}: \mathrm{M}=\mathbf{1 . 3 : 1 )}$ giving a PsA prevalence of $26.4 \%$. Using the Moll \& Wright clinical classification, Oligo/Mono-articular pattern was the most documented (Fig 1). No patient had arthritis mutilans. Enthesitis was found in ALL(100\%) PsA patients (Table 1). Highest frequencies were found in the right iliac, right patella and both plantar fascia (Fig 2). Multiple sites were involved in $87.5 \%$ of patients.

Conclusion: Psoriatic arthritis can not be considered rare among Nigerian Ps patients. Enthesitis has been suggested as the primary finding, and the initial site of inflammation in $\mathrm{PsA}^{2,4}$. Our findings reinforce these theories in an African population. Whilst other studies reported occurence of enthesitis in $30-50 \%$ of PsA patients ${ }^{5}$, our study found $100 \%$. Admittedly though a small study population, it suggests that enthesitis may well be the missing link to finding more PsA patients in Nigeria and Psoriasis patients of West African descent.

References:

[1] Watad A, Cuthbert RJ, Amital H, Mcgonagle D. Enthesitis : Much More Than Focal Insertion Point Inflammation. Curr Rheumatol Rep. 2018;20:41-8.

[2] Barnas JL, Ritchlin CT. Etiology and Pathogenesis of Psoriatic Arthritis. Rheum Dis Clin N Am. 2015;41(4):643-63.

[3] Akpabio AA, Olaosebikan BH, Adelowo OO. Psoriatic Arthritis in Nigeria : Case Series and Literature Review. J Clin Rheumatol. 2018;24(4):183-7.

[4] Sakkas LI, Alexiou I, Simopoulou T, Vlychou M. Enthesitis in psoriatic arthritis. Semin Arthritis Rheum. 2013;43(3):325-34.

\section{Moll \& Wright Classification}

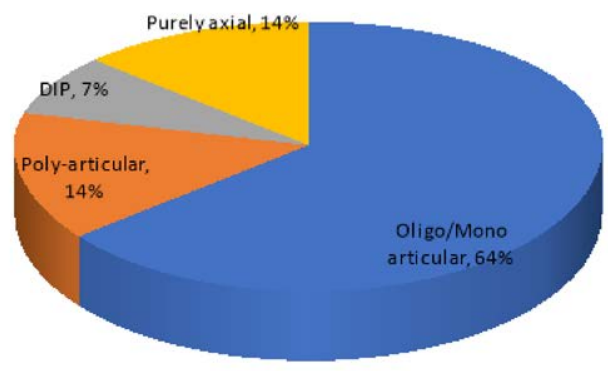

Fig 1. Moll \& Wright articular patterns.

Table 1.

\begin{tabular}{lccr}
\hline VARIABLE & PsA, $\mathrm{n}=14$ & No PsA, $\mathrm{n}=39$ & Sig \\
\hline & $\mathrm{n}(\%)$ & $\mathrm{n}(\%)$ & \\
\hline Inflammatory Eye Disease & & & \\
Yes & $4(28.6)$ & $1(2.6)$ & $0.014 f$ \\
No & $10(71.4)$ & $38(97.4)$ &
\end{tabular}

Table 1.

\begin{tabular}{lccc}
\hline VARIABLE & PsA, $\mathrm{n}=14$ & No PsA, $\mathrm{n}=39$ & Sig \\
\hline Nail Involvement & $\mathrm{n}(\%)$ & $\mathrm{n}(\%)$ & \\
Yes & $8(57.1)$ & $13(33.3)$ & $0.066^{*}$ \\
No & $6(42.9)$ & $26(66.7)$ & \\
Dactylitis & $3(21.4)$ & $0(0)$ & $0.016 f$ \\
Yes & $11(78.6)$ & $39(100.0)$ & \\
No & $14(100)$ & $1(2.6)$ & $0.000 f$ \\
Enthesitis & $0(0)$ & $38(97.4)$ & \\
Yes & & \\
No & &
\end{tabular}

PsA=psoriatic arthritis, $\mathrm{f}=$ Fischer's exact, * $=$ Pearson's chi-square, sig=significance level.

\section{INVOLVED ENTHESEAL SITES}

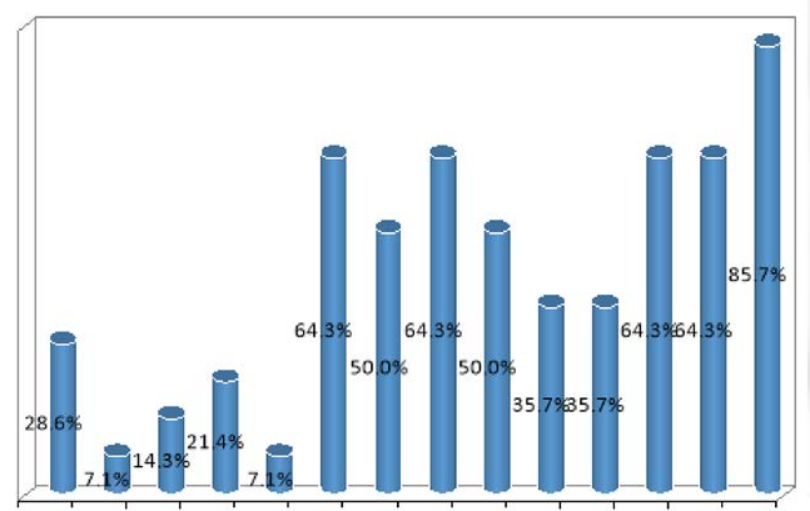

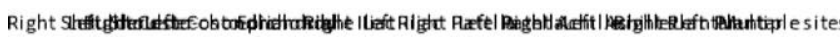

Fig 2. Enthesitis Distribution

Disclosure of Interests: None declared DOI: 10.1136/annrheumdis-2020-eular.1454

\section{AB0734 EFFICACY AND SURVIVAL OF APREMILAST IN PATIENTS WITH PSORIATIC ARTHRITIS AND PSORIASIS IN REAL CLINICAL PRACTICE}

I. Añón Oñate ${ }^{1}$, M. J. Pérez Galán ${ }^{2}$, A. Romero ${ }^{2}$, P. Aceituno ${ }^{3} .{ }^{1}$ Hospital Universitario de Jaén, Rheumatology, Jaén, Spain; ${ }^{2}$ Hospital Universitario de Jaén, Rheumatology, Jaén, Spain; ${ }^{3}$ Hospital Universitario de Jaén, Dermatology, Jaén, Spain

Background: Apremilast (APR) is a phosphodiesterase 4 Inhibitor. APR has been demonstrated to be an effective and safe therapy in the treatment of active psoriatic arthritis (PsA) and psoriasis in patients who were intolerant of or unresponsive to synthetic Disease-modifying Antirheumatic Drugs (DMARDs).

Objectives: To assess the effectiveness and survival rates of APR in a cohort of patients diagnosed with PsA and psoriasis with arthritis in real clinical practice. Methods: An open, longitudinal, prospective, descriptive study. A total of 80 patients diagnosed with PsA or psoriasis with arthritis were included. All patients received the starting dose of oral APR as per the Summary of Product Characteristics and a maintenance dose of $30 \mathrm{mg}$ every 12 hours. The following variables were collected: age, gender, years of evolution, prior treatment with DMARDs, swollen and tender joint counts (SJC, TJC), C-Reactive Protein (CRP), and presence of dactylitis, enthesitis and cutaneous psoriasis. Treatment response was evaluated in all patients at 6,12 and 18 months follow-ups. Efficacy in patients with PsA was evaluated using the Disease Activity in Psoriatic Arthritis (DAP SA)-based criteria: low activity (DAPSA 5-14) and clinical remission (DAPSA 0-4). To assess the level of enthesitis, Maastricht Ankylosing Spondylitis Enthesitis Score (MASES) index was used. Efficacy in patients with psoriasis was evaluated using the Psoriasis Area and Severity Index (PASI)-based criteria: PASI-75 (improvement $\geq 75 \%$ of the baseline PASI). Kaplan-Meier method was used for survival analysis.

Results: Of the 80 patients included in our cohort: 42 patients were diagnosed with PsA and 38 with psoriasis. $57,1 \%$ of patients with PsA and $63,2 \%$ of patients with psoriasis were men with a mean age of $48.2 \pm 11.1$ and $48.2 \pm 14.8$ and mean duration of disease $3.5 \pm 1.4$ and $3.2 \pm 2.6$ years respectively. Most of 